17

18 19

20

21 Running Title: Early Life-History Survival of Cutthroat Trout

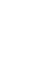

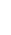
(1)

\section{BRETT ROPER} $U S A$

\section{Early Life-History Survival of Bonneville Cutthroat Trout}

A Study of the Spawning Ecology and
PhaEdRA BUDY ${ }^{1,2}$ AND SARA SEIDEL ${ }^{2}$
${ }^{1}$ U.S. Geological Survey, Utah Cooperative Fish and Wildlife Research Unit,
${ }^{2}$ Department of Watershed Sciences, Utah State University, Logan, Utah 84322-5210, USA
DAVID KOONS

Department of Wildland Resources and the Ecology Center, Utah State University, Logan, Utah 84322-5230, USA

Fish and Aquatic Ecology Unit, U.S. Forest Service, 860 North 1200 East, Logan, Utah 84321,

Key Words: spawning, early life-history survival, redds, Bonneville cutthroat trout, Oncorhynchus clarkii utah, substrate availability, emergence, discharge

21

22

3

24 
Abstract.-We completed a large-scale field experiment in four tributaries of the Logan River, Utah, where the largest metapopulation of imperiled Bonneville cutthroat trout (Oncorhynchus clarkii utah; BCT) persists. We documented the spatial and temporal distribution of BCT spawners, quantified substrate use versus substrate availability, and evaluated differences in hatch and emergence fry success between and among sites in relation to habitat characteristics. We observed considerable variability in the timing, magnitude, and duration of spawning among study areas (streams), in part as a function of a variable, multipeaked hydrograph. Nevertheless, across study areas, $>70 \%$ of redds were constructed on the final descending limb of the hydrograph. Despite large differences in the amount of spawning substrate available, BCT utilized a narrow range of substrate and sizes $(3-80 \mathrm{~mm})$ similar to that utilized by other sub-species of cutthroat trout albeit biased towards larger sizes. Water temperatures generally remained below the recommended range $\left(6-17^{\circ} \mathrm{C}\right)$ for spawning; however, the viability of this meta-population of BCT suggests the recommended temperature range for spawning is likely over-estimated for BCT and/or does not account for local thermal adaptation. Hatch and emergence survival varied from $43-77 \%$ and $39-65 \%$, respectively, among streams, within-stream variability was substantial, and both survival rates declined significantly as a function of increased fine sediment concentrations. Egg development rates were nearly $50 \%$ longer in a high elevation tributary, where redd counts were also lowest. In high, mountain systems with short growing seasons, this incubation delay likely presents a significant growth disadvantage for age-0 trout. Our research enhances our understanding of BCT spawning ecology and early survival and provides critical information for aiding in the development of benchmarks for recovery of BCT. Effective conservation efforts for BCT should 
47 be directed towards minimizing anthropogenic activities that result excess sedimentation in

48 critical spawning tributaries.

In the last century, cutthroat trout (Oncorhynchus clarkii) have experienced large, range-

51 wide reductions in distribution and abundance, due to the combined effects of habitat loss and

52 fragmentation, competition and hybridization with nonnative species, disease, and

53 overharvesting (Behnke 1992; Duncan and Lockwood 2001; Fausch 2008) and now, the

54 additional effects of climate change (Williams et al. 2009). Today, the range of this species is

55 extremely fragmented, with subspecies limited primarily to high elevation lakes and rivers

56 (Behnke 2002). Consequently, of the 14 recognized subspecies of cutthroat trout, two are

57 extinct, three are listed as threatened under the Endangered Species Act and the remaining

58 subspecies are generally imperiled (Williams et al. 2009). Cutthroat trout prefer habitat with

59 clear, cold water, sufficient stream flows, adequate stream side vegetation and habitat complexity

60 and heterogeneity. Their criteria for spawning are thought to be quite specific and require a

61 narrow range of substrate and hydrologic conditions (Hickman and Raleigh 1982; Bjorn and

62 Reiser 1991; Behnke 1992). As a result of such stringent habitat requirements, cutthroat trout

63 are particularly sensitive to human disturbances (e.g., livestock grazing, irrigation diversions,

64 road construction); such sensitivity is likely most pronounced in the important spawning and

65 highly variable early life-history stages (Duff 1988; Behnke 1992; Kershner 1995).

As spring spawners, typical in high mountain streams, the spawning and early life-history

67 stages of cutthroat trout often correspond with the snowmelt and spring spates and are thus 
Isaak et al. 2007), significant gaps remain in our understanding of these life stages for Bonneville cutthroat trout (Oncorhynchus clarkii utah; BCT), the focus of this study (see also Hilderbrand 2003). As with other spring-time spawners, cutthroat trout spawning is thought to be initiated in response to seasonal changes, when environmental conditions reflect the transition from winter to spring with increasing water temperatures, increasing day length and receding flows from spring runoff (Behnke 1992). The environmental conditions that follow spring runoff (e.g., stable flows and warm water temperatures) are representative of high mountain rivers and provide ideal conditions for embryo incubation, fry emergence, and the rearing of juveniles (Behnke 1992; Kershner 1995).

While information describing the spawning ecology and early life-history of BCT is limited, a considerable body of literature provides insight into this critical stage for other species of cutthroat trout. Such studies include the description of physical characteristics of redds (e.g., Thurow and King 1994; Schmetterling 2000), the determination of age at maturity and fecundity of females (e.g., Downs et al. 1997), and the characterization of the relationship of habitat availability, habitat type, and substrate characteristics (e.g., percent fine sediment) to spawning distribution, and redd composition and redd densities (e.g., Magee et al. 1996; Joyce and Hubert 2004). However, to our knowledge, there has been a paucity of research focused on the spawning ecology of BCT, specifically, the quantification of the spawning distribution, spawning duration and timing, fecundity, egg incubation period, emergence time, and egg-to-fry survival of BCT. While restoring these imperiled cutthroat trout populations and protecting and preserving remaining healthy populations remains a top priority and concern (Budy et al. 2007; Williams et al. 2009), these data gaps challenge our ability to identify links between land 
management and cutthroat trout viability and thus limit the effective prioritization of conservation and recovery actions.

In addition to being difficult to quantify and sensitive, for most salmonids, these early life stages typically exhibit high rates of natural mortality for both incubating embryos and emergent fry (e.g., Knight et al. 1999; Kershner 1995). Furthermore, a wide suite of abiotic variables (e.g., water temperature, dissolved oxygen, water velocity, gravel size, percent fine sediment) can be influential in determining early survival (Hickman and Raleigh 1982; Bjorn and Reiser 1991; Kondolf 2000) and disturbances to habitat, via land-use activities, can alter these key physical factors. Hickman and Raleigh (1982) suggest that suitable spawning criteria for cutthroat trout in general include: 1) water temperatures between $6-17^{\circ} \mathrm{C}$, with optimal embryo incubation at $\left.10^{\circ} \mathrm{C}, 2\right)$ mean water column velocities suitable for embryo incubation between $0.11-0.90 \mathrm{~m} / \mathrm{sec}$, with optimal velocities between $0.30-0.60 \mathrm{~m} / \mathrm{sec}$, and 3) a range of substrate sizes for embryo incubation between 3-80 $\mathrm{mm}$ and optimal between $15-60 \mathrm{~mm}$. The critical value for dissolved oxygen is not known at this time for cutthroat trout embryos but is assumed to be similar to that of adult cutthroat trout; optimal dissolved oxygen levels for adult cutthroat trout is $>7 \mathrm{mg} / 1$ at $\leq 15^{\circ} \mathrm{C}$ and $\geq 9 \mathrm{mg} / \mathrm{l}$ at $>15^{\circ} \mathrm{C}$. (Hickman and Raleigh 1992). Overall, the abundance of spawning gravel is perhaps one of the most critical and limiting factors for both successful redd construction and embryo incubation (Kondolf et al. 1991). Despite these general criteria, we know extremely little about how spawning criteria differ among the different species of cutthroat trout, species that are adapted to very different environments.

Land-use activities, such as livestock grazing, can have direct and indirect detrimental impacts on spawning, as redds are extremely vulnerable to trampling by livestock and/or fine sediment accumulation via bankside disturbances from grazing livestock (Gregory and Gamett 
115 116

117 118 119 120 121

122 123 124 125 126 127 128 129 130 131 132

2009). Anthropogenic activities such as road construction and irrigation diversions also have the potential to negatively affect spawning either by fine sediment increases or redd dewatering (Hickman and Duff 1978; Kershner 1995). The effects of fine sediment accumulation can be significant, as sediment caps can form over redds and smother or suffocate incubating embryos and prevent fry emergence (Tappel and Bjornn 1983; Lisle 1989). Given the challenges of quantifying early life-history survival in the wild, lab-based studies have evaluated the relationship between some of these key abiotic variables and cutthroat trout survival at the early life stage in controlled laboratory settings. Young (1991), for example, used Colorado River cutthroat trout (O.c. pleuriticus) eggs in a lab setting to assess the degree to which different proportions of sediment impacted early survival and concluded that egg-to-fry survival declined in respect to the percent fine sediment $13.8 \mathrm{~mm}$ and greater in size. Similarly, while studying the effects of water temperature reduction on survival of cutthroat trout embryos fertilized at $7^{\circ} \mathrm{C}$, Hubert and Gern (1995) found survival to the hatching stage to be lower for those embryos that were at an earlier development stage when water temperatures were reduced to $3^{\circ} \mathrm{C}$. While these studies have advanced our knowledge of the early life stages of cutthroat trout in general, they have not identified mechanistic linkages between habitat quality and quantity, and survival as they occur in nature.

Within the context of native trout conservation and recovery, the overall goal of our research was to gain a better understanding of, and to identify, the underlying factors controlling the spawning ecology and early life stage survival of BCT. To meet that goal, we selected four study streams that captured the natural range of habitat characteristics and BCT redd densities, and focused our research on three primary objectives: 1) documenting the spatial and temporal distribution of BCT spawning among four study streams in the Logan River drainage, 2) 
138 quantifying substrate use versus substrate availability in four study areas in the Logan River 139 drainage, and 3) evaluating differences in hatch and emergence fry success among and within 140 study areas as a function of variation in habitat quality and quantity.

141 
143 Study Area.--Our study area is located within the Logan River drainage, in northern Utah. The 144 headwaters of the Logan River (2,600 m elevation) originate in the Bear River Mountains of 145 southeastern Idaho, flowing approximately 64 river km southwest into the Logan Canyon of 146 northern Utah, eventually draining into the Little Bear River in Cache Valley (see Budy et al. 1472007 for a more detailed site description; Figure 1). The upper Logan River is characterized by a 148 fairly unconfined valley, with moderate to steep gradient channels, coarse sediment loads, and 149 discharge ranging from 0.24 to $7.57 \mathrm{~m}^{3} / \mathrm{s}$. The lower reaches of the river are typified by a 150 dissected canyon, with lower gradient channels, smaller substrate, and fluctuations in discharge 151 from 1.41 to $29.03 \mathrm{~m}^{3} / \mathrm{s}$. The Logan River's hydrograph is dominated by seasonal variation in 152 flow, with snowmelt-driven high flows in the spring (April-May) followed by relatively stable 153 base-flow conditions throughout the remainder of the year. As is typical across the 154 Intermountain West, anthropogenic activities that potentially affect in-stream and riparian habitat 155 in this area are concentrated over summer and early autumn seasons (June-October) and include 156 livestock grazing, horseback riding, dispersed camping, and off-road motorized vehicle use. The 157 Logan River drainage is home to one of the largest remaining metapopulatons of imperiled BCT. 158 Densities in the Logan River drainage currently far exceed those documented for any other BCT 159 population throughout the Bonneville Basin (Budy et al. 2007), making this population ideal for 160 ecological research and also a conservation priority. Based on a pilot study of all tributaries and a subset of mainstem areas in 2007, we $a$ 162 priori chose four study streams within the Logan River drainage to conduct our research (Table 163 1; Figure 1). Spawn Creek (1800 $\mathrm{m}$ in elevation) is a small, spring-fed, 1st-order tributary to 164 Temple Fork, with perennial flows largely controlled by groundwater input, and mean 
165 summertime water temperatures of $9^{\circ} \mathrm{C}$. Temple Fork ( $1745 \mathrm{~m}$ in elevation), also a perennial creek and a tributary to the mainstem of the Logan River, originates from Temple Springs with

167 stream flow largely driven by spring runoff, with mean summertime temperatures of $10^{\circ} \mathrm{C}$.

168 Beaver Creek (2000 m in elevation) and Franklin Basin (2052 $\mathrm{m}$ in elevation) each originate 169 from headwater springs in southern Idaho, with perennial stream flows dominated by spring-

170 runoff, and mean summer water temperatures of $10^{\circ} \mathrm{C}$ and $8^{\circ} \mathrm{C}$, respectively. Franklin Basin and 171 Beaver Creek join to form the mainstem of the Logan River. We chose these sites because they 172 represented a wide range of redd densities and habitat characteristics. In addition, Spawn Creek, 173 anecdotally known as a primary area for BCT spawning (Fleener 1951; Bernard and Israelsen 174 1982), was the site of a recent restoration project, where a fenced exclosure was constructed to 175 prevent cattle access to the entirety of the stream, except for the first 200 meters (Hansen and 176 Budy 2011). In contrast, Temple Fork is susceptible to livestock grazing and the associated 177 impacts of riparian grazing during the spring and summer months.

179 Redd Counts.--We refer to the sample areas within which we surveyed for redds, within each 180 study stream, as "study areas." We initiated biweekly redd counts during the last week of April 181 (2008) in each of our four study areas to document the spatial and temporal distribution of BCT 182 spawning, and continued until spawning activity ceased in July (2008). These study areas 183 constituted the majority of spawning activity as observed during the pilot study of 2007; redd 184 counts were conducted throughout approximately $2.5 \mathrm{~km}$ of each stream, depending on stream 185 topography. In each study area, we identified the presence and location of new redds and 186 classified a redd as an area of cleaned gravel with a characteristic pocket and pillow shape 187 (Hassemer 1993) and recorded the location of each redd using a hand-held Global Position 
188 System unit. We also marked the vegetation near each redd with flagging tape to visually

189 identify redds and prevent double-counting in subsequent surveys. In addition, all efforts were made to visually identify fish presence, whether directly on a redd or nearby.

Discharge and Water Temperature.--We used a combination of stage-height recorders and discharge measurements to project an hourly discharge value throughout spawning in each of our four study areas. In addition, we installed temperature data loggers in each of our four study areas; each logger was set to record temperature every hour.

Spawning Substrate Use and Availability.--To describe the physical characteristics of spawning substrate used by BCT in our four study areas, we measured the gravel composition along the width of each redd via 100-count Wolman pebble surveys (Wolman 1954). Given the conservation status of BCT and our desire to not disturb any redds, the gravel immediately adjacent to each redd was assumed to be of a similar composition to the gravel that was encountered by the spawning female prior to redd construction (Thurow and King 1994). To avoid bias, we measured a randomly selected subset of redds during different times (every one to two weeks as based on new redd activity) throughout the spawning season in each of our four study areas. All attempts were made to measure the gravel composition of an arbitrary but logistically feasible minimum of $30 \%$ of the total redds per study area.

We conducted 55 Wolman pebble surveys in each of our four study areas to characterize substrate availability (Wolman 1954). We delineated each study area ( $2.5 \mathrm{~km})$ into eleven 200 $\mathrm{m}$ reaches. Within each $200 \mathrm{~m}$ reach, we then defined twenty $10-\mathrm{m}$ segments, parallel to stream flow. We then randomly selected five of the twenty transects in each reach to conduct a 100count pebble survey. We assessed the distribution of available substrate in each study area 
212 within the range recommended for cutthroat trout spawning (i.e., 3-80mm; Hickman and Raleigh

213 1982), and calculated the proportion of substrate used versus the proportion available for each

214 substrate size category.

215 Egg-to-Fry Survival Experiment

216 In order to assess differences in fry hatch and emergence success of BCT, we placed

217 hatchery (local fluvial Bear Lake strain) brood-stock, eyed eggs (i.e., day 20 of development at

218 time of installation) into slotted egg incubation boxes and buried the boxes in locations

219 throughout the Logan River drainage on 1 July 2008. Mean daily water temperatures at the time

220 of installation as recorded by the temperature loggers at the egg-box level were $11.4{ }^{\circ} \mathrm{C}$ in Spawn

221 Creek, $9.1{ }^{\circ} \mathrm{C}$ in Temple Fork, $7.2{ }^{\circ} \mathrm{C}$ in Franklin Basin and $10.4{ }^{\circ} \mathrm{C}$ in Beaver Creek. Our

222 primary goal was to install egg boxes in sites where spawning had been observed during the

2232008 redd counts. Sites in which egg boxes were installed are referred to hereafter as "study

224 sites." To determine appropriate sites for egg box installation, we randomly selected a subset of

225 redds in each of our four study areas, and selected nearby sites for our egg boxes, after assessing

226 flow and substrate characteristics via a Wolman pebble survey.

In total, we installed 96 egg boxes throughout our four study areas, with 24 egg boxes

228 installed in each study area; these 24 eggs boxes were separated into 4 study sites, with 6 egg

229 boxes installed per study site. We used an egg box design based on Harris (1973) and modified

230 according to Wood and Budy (2009). Each egg box (tubular in shape) was $10 \mathrm{~cm}$ long by $10 \mathrm{~cm}$

231 wide, and constructed of rigid, tubular polypropylene, with an approximate slot size of $1 \mathrm{~mm}$ by

$2325 \mathrm{~mm}$ to allow adequate delivery of water and oxygen, while still preventing the escape of sac fry

233 and emergent fry. We equipped each egg box with lightweight, flexible polyethylene caps

234 perforated with small holes $(1.5 \mathrm{~mm})$. Each egg box was filled with spawning sized gravel and

235100 eyed, hatchery-fertilized BCT eggs (Utah Division of Wildlife Resources, Mantua Fish 
236 Hatchery). The top 3-4 $\mathrm{cm}$ of each box was left empty to allow room for emerging fry. While

237 we did not record the mean size or shape of the gravel used in the egg boxes, every effort was 238 made to use similar sized gravel in each egg box. Each study site consisted of a T-post driven

239 into the stream bed, with six egg boxes attached to the base of the T-post by wire, buried 240 approximately $10-15 \mathrm{~cm}$ into the gravel to approximate the natural conditions of a spawning 241 cutthroat trout (Smith 1941). In addition, each study site was equipped with a temperature data 242 logger, buried at the depth of the egg boxes and set to record temperature every hour. differing water temperatures among the streams, we first used periodic temperature readings and 245 a relationship between development times and mean temperatures from Merriman (1935) to 246 predict hatch and emergence timing for each of our study sites. At the times predicted for the 247 completion of each stage, we removed half of our egg boxes $(n=3)$ at hatch and the remaining at 248 emergence. If live eggs or live sac-fry were present when we checked the egg boxes at the actual 249 installation site, we reinstalled those egg boxes to allow for further hatching or emergence 250 development. After the majority of eggs had emerged, we transported all egg boxes back to the 251 laboratory, where all fry and any remaining eggs were counted. Survival was calculated as the 252 number of fry alive divided by the number of eggs at initiation.

253 Based on past research of the deleterious impacts of fine sediment accumulation on 254 incubating embryos and developing fry, we evaluated for potential relative differences in fine 255 sediment accumulation within the egg boxes for both the hatch and emergence stages. We 256 collected the accumulated substrate from each egg box, and oven dried $\left(110^{\circ} \mathrm{C}\right.$ for 257 approximately 12 hours) and weighed fine sediment, as defined as less than $4 \mathrm{~mm}$ in diameter. 
258 Relative differences in within egg box sedimentation were expressed as the proportion of fines

259 standardized by the maximum weight of fines observed across all boxes.

260 Statistical Analysis

261 For our third objective, evaluating differences in hatch and emergence fry success

262 among and within sites as a function of variation in habitat quality and quantity, we first used a

263 single factor ANOVA test of hatch and emergence survival rates both among and within study

264 areas. Across site tests compared the mean hatch or emergence survival (dependent variable)

265 across each of four study areas. Within site tests compared the hatch or emergence survival

266 (dependent variable) of each set of three egg boxes within each study area $(n=16)$. Second, as

267 survival values range 0-1 (binomial link function), we used logistic regression to assess the

268 relationship between mean hatch and emergence survival (dependent variables) as a function of

269 fine sediment (independent variable) measured in each of the 16 study sites, across our four

270 study areas (SAS Institute 2005). We standardized the proportion of fine sediment by the

271 maximum weight of fines for both hatch (208 g) and emergence (291 g). Lastly, in order to

272 assess whether sedimentation was more influential at earlier (hatch) or later (emergence)

273 development stages, we compared the statistical significance between fine sediment

274 accumulations at the hatch versus the emergence stage at all study sites, also using a single factor

275 ANOVA.

276 We assessed statistical significance OF all tests using an a priori $\alpha$-level of 0.05 .

277

278

279 Redd Counts.--We observed substantial variability in the timing, magnitude, and duration of

280 BCT spawning among our four study areas during the 2008 spawning season. Notably, the onset

281 of spawning in our two mid-elevation tributaries occurred a month earlier (mid-May) than in our 
282 high-elevation tributaries (mid-June; Figure 2). We identified the onset of spawning in our mid283 elevation tributaries during May 2008 and first counted redds on 13 May at Spawn Creek and 15 284 May at Temple Fork (Figure 2). In Spawn Creek, spawning peaked on 19 May; we observed 285 two peaks in spawning in Temple Fork, with the first peak occurring on 9 June and the second 286 peak occurring on 23 June. In these stream areas, spawning continued through to the first week

287 of July 2008, commencing on 7 July, with 128 and 213 redds counted in Spawn Creek and 288 Temple Fork, respectively. In the high-elevation streams, the first redds were identified on 10 289 June and 16 June, respectively, at Franklin Basin and Beaver Creek (Figure 2), and spawning 290 peaked in early July and was completed 15 July and 23 July for Beaver Creek, and Franklin 291 Basin, respectively.

In total, from May to July 2008, we counted 388 BCT redds throughout tributaries:

293 Temple Fork (85.2 redds/km), Spawn Creek (58.2 redds/km), Beaver Creek (7.6 redds/km), and

294 Franklin Basin $(8.0$ redds $/ \mathrm{km})$. Redds identified in Beaver Creek and Franklin Basin contributed $29512 \%$ to the total number of redds counted, whereas Temple Fork and Spawn Creek contributed $29655 \%$ and $33 \%$, respectively.

297

Discharge and Water Temperature

The winter of 2007/2008 was characterized by an above average snowfall in Logan River drainage, followed by three distinct peaks in the hydrograph during spring and summer months 301 (USGS 2010). Similarly, we observed three distinct, well-spaced peaks in discharge in three of 302 our four study streams (Figure 2). Characteristics of spawning (e.g., timing, magnitude, 303 duration, frequency) appeared to be largely controlled by the respective hydrology of each 304 stream. 
In Temple Fork, spawning activity began with a mean daily discharge of $0.5 \mathrm{~m}^{3} / \mathrm{s}$ on 15

May. Discharge at this time was extremely low, with flows receding from the stream's first large peak in discharge (Figure 2). As discharge increased to a second peak on 20 May, spawning ceased, but resumed again on a very small scale, following the second peak. Spawning increased rapidly after the third and final peak in discharge on 2 June, with $86 \%$ of the redds constructed after the third peak (Figure 2).

In contrast to Temple Fork, stream flows at Spawn Creek were considerably lower at the onset of spawning, with a mean daily discharge of $0.1 \mathrm{~m}^{3} / \mathrm{s}$. Spawn Creek is primarily spring-fed and no pronounced spring-time peaks in discharge were observed (Figure 2). However, we observed the onset of spawning during the lowest spring-time flow. Discharge gradually increased in Spawn Creek during the course of spawning, reaching a peak of $0.2 \mathrm{~m}^{3} / \mathrm{s}$ on July 3 . Similar to the hydrology at Temple Fork, both high-elevation tributaries experienced three peaks in discharge. The magnitude of these peaks, though, was much larger than at Temple Fork. Beaver Creek experienced its first peak event on 20 May (Figure 2). Spawning at Beaver Creek started approximately 12 days after the second peak in discharge at a discharge of 0.9 $\mathrm{m}^{3} / \mathrm{s}$. Spawning activity was relatively low, but stable, as discharge increased to a third and final peak on 18 June. As discharge receded, spawning peaked, with $83 \%$ of the total redds created after the third peak.

Franklin Basin also experienced its first peak in discharge on 20 May, but with a considerably higher discharge (Figure 2), as compared to Beaver Creek. Spawning started on the descending limb of the hydrograph's second peak, at a discharge of $10.2 \mathrm{~m}^{3} / \mathrm{s}$, with one redd identified (Figure 2). As discharge increased to a third peak, spawning started to increase slightly, and six redds were observed before the peak. We counted zero redds during a redd 
count on 19 June, four days before the third and final peak. Seventy one percent of the total redds counted were identified after the last peak.

Daily mean temperatures during the spawning season were variable and fluctuated largely in response to flow (Figure 3). The daily range in water temperatures during the spawning season (May- July) ranged from $4.1-14.0{ }^{\circ} \mathrm{C}$ in Temple Fork, $3.7-16.7{ }^{\circ} \mathrm{C}$ in Spawn Creek, 3.1-10.9 ${ }^{\circ} \mathrm{C}$ in Franklin Basin, and 3.9-13.0 ${ }^{\circ} \mathrm{C}$ in Beaver Creek. In the colder, high elevation streams Beaver Creek and Franklin Basin, spawning activity appeared to increase after mean daily stream temperatures remained above $7^{\circ} \mathrm{C}$.

\section{Substrate Use and Availability}

Bonneville cutthroat trout used a relatively narrow range of substrate throughout our four study areas, but primarily within the range of 3-80 $\mathrm{mm}$ (Figure 4). We did observe a few exceptions to this pattern in Temple Fork and Spawn Creek, where fish used a small proportion of larger particles ( $\geq 90 \mathrm{~mm}$; Figure 4$)$. We quantified the percentage of substrate considered suitable for cutthroat trout spawning (i.e., 3-80mm; Hickman and Raleigh 1982) as approximately 55\% in Temple Fork, $81 \%$ in Spawn Creek, 26\% in Franklin Basin, and 60\% in Beaver Creek.

Egg-to-Fry Survival Experiments

Egg-to-hatch survival (i.e., hatch survival rate) varied substantially both among and within our four study areas (Figure 5; Table 2). Egg boxes in Temple Fork and Beaver Creek supported high rates of hatch survival, with mean hatch survival rates of $77 \%$ and $74 \%$, respectively. In contrast, mean hatch survival rates were lower in Spawn Creek and Franklin Basin, with $43 \%$ and $60 \%$ of eggs hatching, respectively (Table 2). Hatch survival rates were 
350 variable across our four study areas $(P=0.12$; Table 3$)$. We also observed a large degree of

351 spatial variability in hatch survival across sites within some, but not all, study areas (e.g.,

352 Franklin Basin $(P=0.06$; Table 3$)$ and Spawn Creek $(P=0.03$; Table 3$)$.

Similar to the pattern of hatch survival rates, emergence survival rates also varied among

354 and within our four study areas (Figure 5). Emergence survival rates were relatively high in

355 Temple Fork and Beaver Creek, with mean emergence survival rates of $65 \%$ and 57\%,

356 respectively (Table 2). Franklin Basin and Spawn Creek supported lower rates of emergence

357 survival, with mean emergence survival rates of $41 \%$ and $39 \%$, respectively. Despite this

358 variability, mean study area emergence survival rates were not significantly different among the

359 four areas (Table 3). Emergence survival rates were variable within individual study sites for

360 both Franklin Basin $(P=0.03$; Table 3) and Spawn Creek ( $P=0.11$; Table 3$)$ study areas, ranging

361 from 1-61\% and 6-60\%, respectively (Table 2).

362 We observed a relatively wide range of fine sediment accumulation within egg boxes

363 throughout our 16 study sites, with many boxes having little accumulated sediment and a few

364 being nearly full (Table 2). Across study areas fine sediment accumulation within egg boxes was

365 lowest in study sites in Temple Fork and Beaver Creek and higher levels in some study sites

366 throughout Spawn Creek and Franklin Basin. We observed a significant, negative relationship

367 between survival, for both hatch and emergence, and fine sediment (Table 3; Figure 7).

368 Mean daily water temperatures during the course of the experiment were similar and

369 close to the optimal temperature for cutthroat trout embryo incubation in all study areas except

370 Franklin Basin. Mean daily water temperatures during the course of the experiment were $9.0^{\circ} \mathrm{C}$

371 and $10.7^{\circ} \mathrm{C}$ in mid-elevation tributaries, Temple Fork and Spawn Creek, respectively and 10.2

$372{ }^{\circ} \mathrm{C}$ and $7.2{ }^{\circ} \mathrm{C}$ in high-elevation tributaries, Beaver Creek and Franklin Basin, respectively 
373 (Figure 7). Mean daily stream discharge in general during the course of the egg-to-fry

374 experiment was $0.3 \mathrm{~m}^{3} / \mathrm{s}$ in Temple Fork, $3.7 \mathrm{~m}^{3} / \mathrm{s}$ in Franklin Basin, $0.1 \mathrm{~m}^{3} / \mathrm{s}$ in Spawn Creek, 375 and $0.38 \mathrm{~m}^{3} / \mathrm{s}$ in Beaver Creek.

376 Embryo developmental rates in study sites within the high-elevation tributary, Franklin

377 Basin, were considerably later in comparison to our other study sites. Embryo development

378 progressed rapidly in study sites at Spawn Creek and Beaver Creek, with hatching completed on

37912 July, only 12 days after installation. Stream conditions in Temple Fork also supported rapid

380 development, with hatching completed at 14 days after installation. In contrast, fry in Franklin

381 Basin finished hatching 22 days after installation. Fry completed emergence on 28 July in

382 Temple Fork, Spawn Creek, and Beaver Creek, only 28 days after installation, and a full 11 days

383 before emergence completed in Franklin Basin (7 August).

384

\section{Discussion}

Although we observed BCT spawning during a similar time frame (e.g, May-August) as

387 other subspecies of cutthroat trout, we also observed large variability in the onset, magnitude and

388 duration of spawning in response to, in part, a unique, multi-peaked hydrograph. Cutthroat trout

389 strategize to maximize fitness and survival of young in challenging mountain environments by

390 spawning on the descending limb of the hydrograph, such that subsequent flow and water

391 temperatures will be at near optimal conditions for embryo incubation and the rearing of young

392 after hatch (Hickman and Raleigh 1982; Bjorn and Reiser 1991; Behnke 1992). For example,

393 Thurow and King (1994) observed Yellowstone cutthroat trout (YCT; O. c. bouvieri) spawning

394 on the descending limb of the hydrograph in Pine Creek, Idaho, and likewise, Schmetterling 
395 (2000) noted that the spawning period of Westslope cutthroat trout (WSCT; O. c. lewisi) in four tributaries in western Montana occurred after a single peak flow event in May.

Despite the importance of strong annual cues, flexibility in spawn timing in response to a dynamic hydrograph is an evolutionarily robust life-history strategy that has been observed for other species of cutthroat trout. Accordingly we observed pronounced differences in the timing, magnitude, and duration of spawning between just our mid-elevation and high-elevation tributaries. Humboldt cutthroat trout (O. clarkia), for example, a closely related species to the Lahontan cutthroat trout (O. c. henshawi) in Nevada (Nelson et al. 1987) similarly demonstrated two discrete spawning periods following two discrete peak flow events in April and May, respectively. As such, we believe the variation we observed in the timing of BCT spawning 405 among our four study areas may be explained, in part, by characteristics of the hydrograph. The 406 spring and summer of 2008 represented a somewhat unique year for the Logan River, both 407 spatially and temporally, with three peak flow events occurring from May-July (USGS 2010). 408 More typically, the Logan River has either one, large snowmelt driven pulse or two smaller 409 pulses, with the majority of spawning likely occurring on the descending limb of the final peak 410 in the hydrograph. In this study, while we did observe spawning initiating in response to the first 411 two peak flow events of the spring and summer, the majority of spawning was delayed until after 412 the third peak flow event, when spawning conditions (e.g., water temperature, discharge) 413 appeared closer to optimal conditions. Interestingly, in Spawn Creek, one of our small, first 414 order study tributaries, the spring-runoff spate is insignificant in magnitude and the hydrograph 415 demonstrates little variability due to perennial spring inputs. In this study area, BCT may be 416 cueing into flows either at Temple Fork and/or the mainstem of the Logan River as they stage 
417 and migrate through to Spawn Creek (Figure 1) and/ or stream water temperature (e.g., Homel 418 and Budy 2008; Seidel 2009).

Water temperature is also known to play an important role in cutthroat trout spawning

420 (Behnke 2002), and notably, the temperature ranges we observed in our four study streams were

421 considerably lower than spawning temperatures observed for other subspecies of cutthroat trout.

422 In each of our four study streams, water temperatures were often below the recommended range

423 for cutthroat trout spawning (e.g., $6-17^{\circ} \mathrm{C}$; Hickman and Raleigh 1982) throughout the

424 spawning season. Furthermore, in the coldest, high elevation streams, BCT appeared to delay

425 spawning until stream temperatures remained above $7{ }^{\circ} \mathrm{C}$. Thurow and King (1994) observed

426 YCT spawning in a mean water temperature range of $10-14{ }^{\circ} \mathrm{C}$, a minimum water temperature

427 range of $4-9^{\circ} \mathrm{C}$, and a maximum water temperature range of $16-20^{\circ} \mathrm{C}$. In addition, the onset

428 of spawning was not observed until mean daily temperatures were above $10^{\circ} \mathrm{C}$ and minimum

429 daily temperatures above $4{ }^{\circ} \mathrm{C}$; however, they did not measure or report associated discharge. In

430 this study, the unique multi-peaked hydrograph contributed to non-linear patterns of warming

431 and cooling across the spring season, in contrast to a consistent pattern of warming along a

432 descending limb of the hydrograph, and temperatures were colder than reported elsewhere during

433 spawning. Given the extremely large size and viability of this meta-population of BCT (Budy et

434 al. 2007), we suggest the recommended temperature range for spawning in the published Habitat

435 Suitability Index for cutthroat trout in general (Hickman and Raleigh 1982) is likely over-

436 estimated and/or does not account for local thermal adaptation (e.g., Keleher and Rahel 1996;

437 Jensen et al. 2003).

While discharge and temperature may provide important cues for spawning, suitable

439 substrate must be available for successful spawning, incubation and emergence (Kondolf and 
440 Wolman 1993; Kondolf 2000). Tributary streams, such as those studied herein, often represent 441 ideal spawning conditions including a high availability of suitable sized substrate (Bjornn and

442 Reiser 1991; Knapp and Vredenburg 1996; Magee et al. 1996). While we documented BCT 443 spawning over a large spatial scale, from mid-to-high elevation tributaries, the size range of 444 substrate used was relatively narrow but still corresponded with the size range available. For 445 example, Franklin Basin is dominated by a steep gradient and cobble-boulder sized substrate 446 with limited suitable spawning gravel available. The spawning habitat that is available is sub447 optimal, restricted to marginal areas along the bank and silty in composition; these areas along 448 the bank are also highly susceptible to cattle intrusion during the spring and summer months 449 (Seidel 2009; Hansen and Budy 2011). Our observed low redd counts appeared to coincide with 450 the low abundance of available spawning substrate in Franklin Basin (and perhaps also colder 451 stream temperatures; see above). These results confirm that even in systems where fish densities 452 are high overall and habitat is near pristine, the local abundance of spring-spawning salmonids 453 may be limited at the reproductive stage, if spawning substrate availability is low and/or stream 454 conditions are unsuitable for the successful spawning and rearing of young (Magee et al. 1996; $455 \quad$ Knapp et al. 1998).

Despite differences in the amount of available spawning substrate among our four study 457 areas, BCT appeared to primarily utilize substrate within the range recommended for cutthroat 458 trout spawning in all four study areas (e.g., 3 - 80mm, Hickman and Raleigh 1982). BCT used 459 substrate similar to that of WSCT (e.g., $0.07-50.8 \mathrm{~mm}$, Magee et al. 1994; $6-110 \mathrm{~mm}$, 460 Schmetterling 2000) but of sizes greater than the range observed for Snake River spotted 461 cutthroat trout (O.c. [proposed] behnkei; 2-20 mm; Joyce and Hubert 2004). The variability 
462 observed in spawning substrate use among subspecies of cutthroat trout may simply be a

463 function of fish size (i.e., larger fish utilize large substrate) and/or available substrate.

465 of redds, our study did have important and obvious limitations and constraints. Observer error

466 can limit the accuracy and precision of redd counts, when counts are used as a technique to

467 monitor adult fish populations (Dunham et al. 2001; Al-Chokhachy et. al 2005; Muhlfeld et al.

468 2006). The purpose of our redd counts, though, was not to monitor and/or estimate adult BCT

469 populations, but rather, to provide critical information in furthering our understanding of the

470 temporal and spatial distribution of BCT throughout the Logan River drainage. Nevertheless,

471 observers may have underestimated the number of redds and/or the date of the onset of

472 spawning, especially in our high-elevation study streams, where flow conditions were high and

473 turbid into late June. However, we might expect that in years when the magnitude, frequency,

474 and duration of peak flows events is smaller, flow and water conditions (i.e., turbidity levels)

475 could potentially be suitable for spawning earlier in the spring and summer than what we

476 observed in 2008. As such, our identification of the onset of BCT spawning in our four study

477 areas may have been accurate, and the low density of redds observed in Franklin Basin and

478 Beaver Creek may simply be a function of a shorter available spawning season, due to

479 hydrologic stream conditions (e.g., Hickman and Raleigh 1982; Thurow and King 1994).

In addition to the constraints on our ability to identify the onset of spawning, it is

481 important to understand the somewhat unavoidable limitations of estimating hatch and

482 emergence survival even with a large-scale field experiment and substantial degree of effort.

483 Our estimates of survival are likely an overestimation of survival under natural conditions.

484 Incubating embryos, sac fry and emergent fry were protected, by a large degree, from both 
485 abiotic and biotic factors, such as scouring flows, predation (e.g., by sculpin, Cottus bairdii), and to a certain degree, anthropogenic impacts (e.g., trampling from recreationists and/or grazing

487 livestock; Kershner 1995; DeVries 1997; Gregory and Gamett 2009). In contrast, some boxes

488 may have experienced artificially high sediment accumulation based simply on small

489 microhabitat differences in location within the artificial redd (see further discussion below).

490 Despite these potential limitations, our estimates of BCT hatch and emergence survival provided 491 an excellent description of the relative variability in early survival among a wide range of habitat 492 conditions and provides novel information on a life stage for which there was little previously 493 known.

In our experiments, we observed variability in hatch and emergence survival rates both 495 among but also within our four study areas, especially throughout study sites in tributaries, 496 Spawn Creek and Franklin Basin. Such variability is likely driven by important microhabitat site 497 differences in intragravel conditions such as the proportion of fine sediment and other substrate 498 characteristics (Bjorn and Reiser 1991). The negative relationship between salmonid early life499 stage survival and fine sediment we observed herein has been firmly and mechanistically 500 documented in the literature (e.g., Chapman 1988; Julien and Bergeron 2006). Further, using 501 Colorado River cutthroat trout (O.c. pleuriticus) eggs in a lab setting, Young (1991) assessed the 502 degree to which different proportions of sediment impacted early survival, concluding that egg503 to-fry survival was highest with geometric mean particle sizes $13.8 \mathrm{~mm}$ and greater. Kondolf 504 (2000) similarly highlights the importance of water flow through redds for the delivery of 505 dissolved oxygen and the removal of metabolic waste. Fine sediment accumulation within the 506 incubation gravel can greatly impede these critical and necessary processes and may explain the 507 differences we observed in hatch survival in emergence survival in Franklin Basin. In contrast, 
508 in Spawn Creek, we actually observed a low mean hatch survival and a low mean amount of fine 509 sediment in one of our four study sites, highlighting the role of other environmental conditions,

510 perhaps outside of the egg boxes. Further, it is also important to note that the level of fine

511 sediment we observed in our egg boxes may be a function of natural conditions, anthropogenic

512 conditions, our egg box design, or some combination of the three. Regardless of the ultimate

513 determinate of the proportion fines, the negative relationship we observed between fine sediment

514 and hatch and emergence survival rates has important and obvious implications for land-use

515 management and BCT conservation (e.g., McHugh et al. 2004). In systems or areas that are

516 naturally near the upper limits for fine sediments, even a small degree of increase in

517 sedimentation can have large effects on early survival. Based on these results, if protection of

518 BCT is a management priority, efforts should be made to prevent excessive sedimentation in 519 critical spawning streams.

520 In addition to fine sediment, water temperature also serves as a key physical factor that

521 has a strong, mechanistic influence on salmonid early life-stage survival and embryo

522 development. In our study, embryo development was delayed in the cold, high-elevation

523 tributary, Franklin Basin, and fry emerged approximately 10 days later in Franklin Basin than in

524 Temple Fork, Spawn Creek, and Beaver Creek. The relationship between delayed cutthroat trout

525 embryo development and cooler and/or decreasing water temperatures has been documented

526 extensively in the lab (e.g., Merriman 1935; Stonecypher et al. 1994; Hubert and Gern 1995),

527 with Hickman and Raleigh (1982) recommending optimal water temperatures for cutthroat trout

528 embryo incubation at $10^{\circ} \mathrm{C}$. Mean daily water temperatures in all study sites except Franklin

529 Basin were close to the optimal temperature for embryo incubation, while in contrast, mean daily

530 temperatures observed in study sites in Franklin Basin were on average at least $2{ }^{\circ} \mathrm{C}$ cooler over 
531 the course of the experiment (e.g., $\left.\sim 7^{\circ} \mathrm{C}\right)$. Fry that emerge earlier in the summer may have a

532 greater potential to reach the critical body size need to successfully survive winter, as opposed to

533 fry that emerge later in the season and lack the body size and mass needed to endure the harsh

534 winter conditions common in the Logan River drainage (Cerven 1973; Smith and Griffith 1994).

535 Based on the results of our spawning surveys, as well as our egg-to-fry survival experiments,

536 high-elevation tributary, Franklin Basin appears to be naturally less suited for both spawning and

537 embryo incubation, relative to the conditions observed in the other three tributaries. These

538 results have important implications for local restoration activities (Budy et al. 2007) and

539 demonstrate a template for prioritizing conservation actions more broadly.

The conservation and recovery of imperiled, native fish species poses several significant

541 recovery challenges. Specifically, identifying the life stage(s) most limiting for a given fish

542 species and then prioritizing conservation efforts accordingly can be a complicated and

543 challenging endeavor (e.g., Budy and Schaller 2007; Williams et al. 2009). Our study is one of

544 few to quantify both the spawning ecology and early life-history survival of cutthroat trout via a

545 large-scale, replicated field study. The variability we observed in the timing of BCT spawning,

546 and redd densities appeared to be strongly linked to variation in in-stream habitat conditions

547 (e.g., discharge, substrate), and as such, has important implications for the conservation and

548 restoration of spawning habitat for BCT range wide. In addition, the results of our BCT egg-to-

549 fry survival experiments highlighted the deleterious effects of fine sediment to hatch and

550 emergence survival. By conducing this studying in a system where the quality and connectivity

551 of habitat still supports a very large metapopulation of BCT, our research enhances our

552 understanding of cutthroat trout spawning ecology and early survival and provides critical 
553 information for aiding in the development of benchmarks for the recovery and persistence of

554 BCT in this as well as other systems.

555 
557 This research was primarily funded by the United States Forest Service, Utah Division of

558 Wildlife Resources, Project XII, Sport Fisheries Research, Grant Number F-47-R, Segment 20

559 and in-kind support from the U.S. Geological Survey, Utah Cooperative Fish and Wildlife

560 Research Unit. Special thanks to Gary Thiede for providing technical advice and logistical

561 oversight of our field crews, and graduate students in the Fish Ecology Laboratory at Utah State

562 University. Susan Durham provided statistical advice and assistance and Christy Meredith

563 assisted with GIS and graphical issues. We would also like to thank Jeremiah Wood for

564 intellectual and field contributions; a long list of seasonal technicians also assisted with field

565 work. Any use of trade product or firm names is for descriptive purposes only and does not

566 imply endorsement by the U.S. Government.

567

568

569

570

571

572

573

574

575

576

577

578

579

580

581

582 583

\section{References}

Al-Chokhachy, R., P. Budy, and H. Schaller. 2005. Understanding the significance of redd counts: a comparison between two methods for estimating the abundance of and monitoring bull trout populations. North American Journal of Fisheries Management 25:1505-1512.

Beauchamp, D.A., P.E. Budy, B.C. Allen, and J.M. Godfrey. 1994. Timing, distribution and abundance of kokanees spawning in a Lake Tahoe tributary. Great Basin Naturalist 54: 130-141.

Behnke, R. 1992. Native trout of western North America. American Fisheries Society, Monograph 6, Bethesda, Maryland.

Behnke, R. 2002. Trout and salmon of North America. Free Press, New York, New York. 
596

597 598

599

600 601

602

603 604 605 606 607 608 609 610 611

Bernard, D.R., and E.K. Israelsen. 1982. Inter- and intrastream migration of cutthroat trout (Salmo clarki) in Spawn Creek, a tributary of the Logan River, Utah. Northwest Science 56:148-157.

Bjorn, T.C., and D.W. Reiser. 1991. Habitat requirements of salmonids in streams: Influences of forest and rangeland management on salmonid fisheries and their habitats. American Fisheries Society Special Report 19:83-138.

Budy, P., G.P, Thiede, and P. McHugh. 2007. Quantification of the vital rates, abundance and status of a critical, endemic population of Bonneville cutthroat trout. North American Journal of Fisheries Management 27:593-604.

Budy, P., and H. Schaller. 2007. Evaluating tributary restoration potential for Pacific salmon recovery. Ecological Applications 17:1068-1086.

Cerven, D.R. 1973. Overwinter mortality of trout in Temple Fork of the Logan River. Thesis, Utah State University, Logan, Utah.

Chapman, D.W. 1988. Critical review of variables used to define effects of fines in redds of large salmonids. Transactions of the American Fisheries Society 117:1-21.

DeVries, P. 1997. Riverine salmonid egg burial depths: review of published data and implications for scour studies. Canadian Journal of Aquatics and Fisheries Science 54: $1685-1698$.

Downs, C.C., R.G. White, and B.B. Shepard. 1997. Age at sexual maturity, sex ratio, fecundity, and longevity of isolated headwater populations of westslope cutthroat trout Oncorhynchus clarki lewisi. North American Journal of Fisheries Management 17:85-92.

Duncan, J. R. and Lockwood, J. L., 2001. Extinction in a field of bullets: a search for 
624

625

626

627

628

629

630

causes in the decline of the world's freshwater fishes. Biological Conservation 102:97105.

Dunham, J., B. Rieman, and K. Davis. 2001. Sources and magnitude of sampling error in redd counts for bull trout. North American Journal of Fisheries Management 21:343-352.

Duff, D.A. 1988. Bonneville cutthroat trout: current status and management. Pages 121127 in R. E. Gresswell, editor. Status and management of interior stocks of cutthroat trout. American Fisheries Society, Symposium 4, Bethesda, Maryland.

Fausch, K.D. 2008. A paradox of trout invasions in North America. Biological Invasions 10:685-701.

Fleener, G.G. 1951. Life-history of the cutthroat trout, Salmo clarki Richardson, in the Logan River, Utah. Transactions of the American Fisheries Society 81:235-248.

Gregory, J.S. and B.L. Gamett. 2009. Cattle trampling of simulated bull trout redds. North American Journal of Fisheries Management. 29:361-366.

Hansen, E. S., and P. Budy. 2011. The potential of passive stream restoration to improve ecosystem health and minimize the impact of disease on fish: A short-term assessment. Journal of the North American Benthological Society 30:573-588.

Harris, G.S. 1973. A simple egg box planting technique for estimating the survival of eggs deposited in stream gravel.

Hassemer, P.F. 1993. Redd count manual. Idaho Department of Fish and Game, Boise, Idaho.

Hickman, T. J., and D. A. Duff. 1978. Status of cutthroat trout subspecies in the western Bonneville basin. Great Basin Naturalist 38:193-202. 
647

648

649

650

651

652

653

654

655

656

657

658

659

660

661

662

663

664

665

666

667

668

669

670

671

672

673

674

675 Keleher, C.J., and F.J. Rahel. 1996. Thermal limits to salmonid distributions in the Rocky

Hickman, T., and R.F. Raleigh. 1982. Habitat suitability index models: cutthroat trout. U.S.D.I. Fish and Wildlife Service. FWS/OBS-82/10.5. 38 pages.

Hilderbrand, R. H. 2003. The roles of carrying capacity, immigration, and population synchrony on persistence of stream-resident cutthroat trout. Biological Conservation 110:257-266.

Homel, K., and P. Budy. 2008. Temporal and spatial variability in the migration patterns of juvenile and subadult bull trout in northeastern Oregon. Transactions of the American Fisheries Society 137: 869-880.

Hubert, W. A., and W. A. Gern. 1995. Influence of embryonic stage on survival of cutthroat trout exposed to temperature reduction. Progressive Fish-Culturist 57:326-328.

Isaak, D. J., R.F. Thurow, B.E. Rieman, and J.B. Dunham. 2007. Chinook salmon use of spawning patches: Relative roles of habitat quality, size, and connectivity. Ecological Applications 17:352-364.

Jensen, A.J., Forseth, T. and Johnson, B.O. 2003. Latitudinal variation in growth of young brown trout Salmo trutta. Journal of Animal Ecology 69: 1010-1020.

Joyce, M.P. and W. A. Hubert. 2004. Spawning ecology of Finespotted Snake River cutthroat trout in spring streams of the Salt River Valley, Wyoming. North American Naturalist 64:78-85.

Julien, H.P., and N.E. Bergeron. 2006. Effect of fine sediment infiltration on Atlantic salmon (Salmo salar) embryo survival. Hydrobiologia, 563:61-71. 
679

680

681

682

683

684

685

686

687

688

689

690

691

692

693

694

695

696

697

698

699

700

701

702

703

704

705

706

Mountain region and potential habitat loss due to global warming: a geographic information system (GIS) approach. Transactions of the American Fisheries Society 125:1-13.

Kershner, J. 1995. Bonneville cutthroat trout. Pages 28-35 in M. K. Young, editor. Conservation assessment for inland cutthroat trout. General Technical Report, RM-256. USDA Forest Service, Ft. Collins, Colorado.

Knapp, R. A., and V. T. Vredenburg. 1996. Spawning by California golden trout: characteristics of spawning fish, seasonal and daily timing, redd characteristics, and microhabitat preferences. Transactions of the American Fisheries Society 125:519-531.

Knapp, R. A., Vredenburg, V. T., and Matthews, K. R. 1998. Effects of stream channel morphology on golden trout spawning habitat and recruitment. Ecological Applications 8: 1104-1117.

Knight, C.A., R.W. Orme, and D.A. Beauchamp. 1999. Growth, survival, and migration patterns of juvenile adfluvial Bonneville cutthroat trout in tributaries of Strawberry Reservoir, Utah. Transactions of the American Fisheries Society 128:553563.

Kondolf, G. M., and M. G. Wolman. 1993. The sizes of salmonid spawning gravels. Water Resources Research 29:2275-2285.

Kondolf, G.M., G.F. Cada, M.J. Sale and R. Felando. 1991. Distribution and stability of potential salmonid spawning gravels in steep boulder-bed streams of the eastern Sierra Nevada. Transactions of the American Fisheries Society 120:177-186.

Kondolf, G.M. 2000. Assessing salmonid spawning gravel quality. Transactions of the American Fisheries Society 129:262-281. 
Lisle, T. E. 1989. Sediment transport and resulting deposition in spawning gravels, north coastal California. Water Resources Research 25:1303-1319.

Magee, J.P., T.E. McMahon, and R.F. Thurow. 1996. Spatial variation in spawning habitat of cutthroat trout in a sediment-rick stream basin. Transactions of the American Fisheries Society 125:768-779.

Merriman, D., 1935. The effect of temperature on the development of the eggs and larvae of the cutthroat trout (Salmo clarkii clarkii Richardson). Journal of Experimental Biology 12: 297-305.

McHugh, P., P. Budy, and H. Schaller. 2004. A model-based assessment of the potential response of Snake River-summer chinook salmon to habitat improvements. Transactions of the American Fisheries Society 133:622-638.

Muhlfeld, C.C., M.L. Taper, D.F. Staples, and B.B. Shepard. 2006. Observer error structure in bull trout redd counts in Montana streams: Implications for inference on true redd numbers. Transactions of the American Fisheries Society 135:643-654.

Nelson, R.L., W.S. Platts, and O. Casey. 1987. Evidence for variability in spawning behavior of interior cutthroat trout in response to environmental uncertainty. Great Basin Naturalist 47:480-487.

SAS Institute. 2005. SAS version 9.0.1. SAS Institute, Cary, North Carolina.

Schmetterling, D.A. 2000. Redd characteristics of fluvial westslope cutthroat trout in four tributaries to the Blackfoot River, Montana. North American Journal of Fisheries Management 20:776-783.

Schmetterling, D.A. 2001. Seasonal movements of fluvial westslope cutthroat trout in 
the Blackfoot River drainage, Montana. North American Journal of Fisheries Management 21:507-520.

Seidel, S.E. 2009. Exploring the spawning dynamics and identifying limitations to the early lifehistory survival of an important, endemic fish species. Thesis, Utah State University, Logan, Utah.

Smith, O.R. 1941. The spawning habits of cutthroat and eastern brook trouts. Journal of Wildlife Management 5:461-471.

Smith, R.W., and J.S. Griffith. 1994. Survival of rainbow trout during their first winter in the Henrys Fork of the Snake River, Idaho. Transactions of the American Fisheries Society $123: 747-756$.

Stonecypher, R.W., Jr., W.A. Hubert, and W.A. Gern. 1994. Effect of reduced incubation temperatures on survival of trout embryos. Progressive Fish-Culturist 56:180-184.

Tappel, P. D., and T. C. Bjornn. 1983. A new method of relating size of spawning gravel to salmonid embryo survival. North American Journal of Fisheries Management 3:123-135.

Thurow, R.T., and J.G. King. 1994. Attributes of Yellowstone cutthroat trout redds in a tributary of the Snake River, Idaho. Transactions of the American Fisheries Society $123: 37-50$.

USGS (US Geological Survey) 2010. Real-time water data for the USA. Available on website: http://waterdata.usgs.gov/nwis/rt. 23 August 2010.

Williams, J.E., A. L. Haak, H.M., Neville, and W.T. Colyer. 2009. Potential consequences of climate change to persistence of cutthroat trout populations. North American Journal of Fisheries Management 29:533-548. 
768 Wolman, M.G. 1954. A method of sampling coarse river-bed material Transactions American 769 Geophysical Union 3(6):951-956.

770

771 Wood, J. R., and P. Budy. 2009. The role of environmental factors in determining early survival 772 773 and invasion success of exotic brown trout. Transactions of the American Fisheries

774

775 Young, M.K. 1991. Selection of measures of substrate composition to estimate survival 776 to emergence of salmonids and to detect changes in stream substrates. North American

777 Journal of Fisheries Management 11:339-346.

778

779 
780 Table 1. Mean baseflow, mean width, length of survey reach and elevation of our four study 781 streams of our four study streams. Mean baseflow calculated as the mean daily flows during 782 baseflow conditions, August to October.

\begin{tabular}{lcccc}
\hline Study stream & $\begin{array}{c}\text { Mean baseflow } \\
\left(\mathrm{m}^{3} / \mathrm{s}\right)\end{array}$ & $\begin{array}{c}\text { Mean width } \\
(\mathrm{m})\end{array}$ & $\begin{array}{c}\text { Length of survey } \\
\text { reach }(\mathrm{m})\end{array}$ & $\begin{array}{c}\text { Elevation } \\
(\mathrm{m})\end{array}$ \\
\hline Spawn Creek & 0.11 & 1.85 & 2200 & 1800 \\
Temple Fork & 0.37 & 3.71 & 2500 & 1745 \\
Beaver Creek & 0.04 & 4.41 & 3000 & 2000 \\
Franklin Basin & 0.31 & 8.41 & 3000 & 2052 \\
\hline
\end{tabular}

783

784

785

786

787

788

789

790

791 
792 Table 2. Egg-to-fry survival rates (hatch and emergence), hatch and emergence times, and

793 measurements of key abiotic variables for tributary sites. Daily mean temperature was calculated

794 over the course of each study sites' respective hatch and emergence periods. Egg boxes were

795 installed in all study sites on 1 July, 2008.

\begin{tabular}{|c|c|c|c|c|c|c|c|c|}
\hline Site & $\begin{array}{c}\text { Number } \\
\text { of days } \\
\text { to hatch } \\
\text { ending }\end{array}$ & $\begin{array}{c}\text { Mean } \\
\text { hatch } \\
\text { survival } \\
(\%)\end{array}$ & $\begin{array}{c}\text { Mean water } \\
\text { temperature } \\
\left({ }^{\circ} \mathrm{C}\right)\end{array}$ & $\begin{array}{c}\text { Mean } \\
\text { fine } \\
\text { sediment } \\
(\mathrm{g})\end{array}$ & $\begin{array}{l}\text { Number of } \\
\text { days to } \\
\text { emergence } \\
\text { ending }\end{array}$ & $\begin{array}{c}\text { Mean } \\
\text { emergence } \\
\text { survival } \\
(\%)\end{array}$ & $\begin{array}{c}\text { Mean water } \\
\text { temperature } \\
\left({ }^{\circ} \mathrm{C}\right)\end{array}$ & $\begin{array}{l}\text { Mean } \\
\text { fine } \\
\text { sediment } \\
(\mathrm{g})\end{array}$ \\
\hline \multicolumn{9}{|c|}{ Mid-Elevation Tributaries } \\
\hline Temple Fork 1 & 14 & 65 & 8.99 & 26 & 28 & 42 & 9.45 & 34 \\
\hline Temple Fork 2 & 14 & 80 & 8.99 & 19 & 28 & 63 & 9.44 & 32 \\
\hline Temple Fork 3 & 14 & 84 & 8.51 & 22 & 28 & 84 & 8.99 & 36 \\
\hline Temple Fork 4 & 14 & 80 & 8.48 & 43 & 28 & 72 & 8.97 & 30 \\
\hline Spawn Creek 1 & 12 & 23 & 10.73 & 125 & 28 & 6 & 10.80 & 238 \\
\hline Spawn Creek 2 & 12 & 22 & 10.68 & 15 & 28 & 31 & 10.79 & 88 \\
\hline Spawn Creek 3 & 12 & 79 & 10.60 & 63 & 28 & 60 & 10.74 & 32 \\
\hline Spawn Creek 4 & 12 & 49 & 10.60 & 40 & 28 & 60 & 10.73 & 69 \\
\hline Mean & & 60 & 9.70 & 44 & & 52 & 9.99 & 70 \\
\hline \multicolumn{9}{|c|}{ High-Elevation Tributaries } \\
\hline Beaver Creek 1 & 12 & 67 & 10.18 & 26 & 28 & 61 & 11.21 & 49 \\
\hline Beaver Creek 2 & 12 & 74 & 9.95 & 22 & 28 & 44 & 10.36 & 58 \\
\hline Beaver Creek 3 & 12 & 75 & 9.91 & 29 & 28 & 65 & 10.28 & 91 \\
\hline Beaver Creek 4 & 12 & 81 & 9.86 & 16 & 28 & 58 & 10.23 & 49 \\
\hline Franklin Basin 1 & 22 & 21 & 6.98 & 141 & 38 & 1 & 7.50 & 291 \\
\hline Franklin Basin 2 & 22 & 62 & 7.04 & 56 & 38 & 48 & 7.65 & 124 \\
\hline Franklin Basin 3 & 22 & 75 & 6.65 & 85 & 38 & 61 & 7.09 & 117 \\
\hline Franklin Basin 4 & 22 & 83 & 6.39 & 25 & 38 & 55 & 6.67 & 55 \\
\hline Mean & & 67 & 8.37 & 50 & & 47 & 8.87 & 104 \\
\hline
\end{tabular}


798 Table 3. Results of statistical tests for BCT hatch and emergence survival. Across site tests

799 compared the mean hatch or emergence survival at each of the four study areas. Within site tests

800 compared the hatch or emergence survival (dependent variables) of each set of three egg boxes

801 within each study area. See Methods for additional detail.

\begin{tabular}{|c|c|c|c|c|}
\hline Measurement & Statistical test & DF & F-statistic & P-value \\
\hline \multicolumn{5}{|l|}{ Hatch stage survival } \\
\hline Across study sites & Single factor ANOVA & 3,12 & 2.44 & 0.12 \\
\hline Temple Fork & Single factor ANOVA & 3,8 & 1.08 & 0.41 \\
\hline Spawn Creek & Single factor ANOVA & 3,8 & 4.92 & 0.03 \\
\hline Beaver Creek & Single factor ANOVA & 3,8 & 1.79 & 0.23 \\
\hline Franklin Basin & Single factor ANOVA & 3,8 & 3.78 & 0.06 \\
\hline $\begin{array}{l}\text { Mean hatch fine sediment vs. mean } \\
\text { hatch survival (all study sites } \\
\text { combined) }\end{array}$ & Logistic regression & 1 & $\mathrm{n} / \mathrm{a}$ & $<0.001$ \\
\hline \multicolumn{5}{|l|}{ Emergence stage survival } \\
\hline Across study sites & Single factor ANOVA & 3,12 & 1.38 & 0.30 \\
\hline Temple Fork & Single factor ANOVA & 3,8 & 2.58 & 0.13 \\
\hline Spawn Creek & Single factor ANOVA & 3,8 & 2.80 & 0.12 \\
\hline Beaver Creek & Single factor ANOVA & 3,8 & 0.27 & 0.84 \\
\hline Franklin Basin & Single factor ANOVA & 3,8 & 5.24 & 0.03 \\
\hline $\begin{array}{l}\text { Mean emergence fine sediment vs. } \\
\text { mean emergence survival (all study } \\
\text { sites combined) }\end{array}$ & Logistic regression & 1 & $\mathrm{n} / \mathrm{a}$ & $<0.001$ \\
\hline \multicolumn{5}{|l|}{ Hatch vs. Emergence } \\
\hline Fine sediment & Single factor ANOVA & 1,29 & & 0.20 \\
\hline
\end{tabular}


804 Figure 1. Map of the Logan River drainage, in northern Utah. Study streams are highlighted and 805 include mid-elevation tributaries, Temple Fork and Spawn Creek and high-elevation tributaries,

806 Franklin Basin and Beaver Creek. The river flows from north to southwest.

807

808

Figure 2. Number of BCT redds counted (bars) and average daily discharge (line; $\mathrm{m}^{3} / \mathrm{s}$ ) during 809 the 2008 BCT spawning season in Beaver Creek, Franklin Basin, Spawn Creek, and Temple 810 Fork, from top to bottom.

811

812 Figure 3 . Number of BCT redds counted (bars) and average daily temperature (line; ${ }^{\circ} \mathrm{C}$ ) during

813 the 2008 BCT spawning season in Beaver Creek, Franklin Basin, Spawn Creek, and Temple

814 Fork, from top to bottom. Note changes in right and left y-axis scales.

815

816 Figure 4. Proportion of substrate used versus substrate available in Beaver Creek, Franklin

817 Basin, Spawn Creek, and Temple Fork, from top to bottom. Substrate size was measured using a

818 Wolman pebble count; sizes represent minimum size bins.

819

820 Figure 5. Percent hatch and emergence survival for study sites (from low to high elevation) in

821 study streams Beaver Creek, Franklin Basin, Spawn Creek, and Temple Fork, from top to

822 bottom. Dark bars represent percent hatch survival and gray bars represent percent emergence

823 survival. The dashed line represents the mean survival, as averaged over hatch and emergence,

824 per study stream. Please note that we did conduct two separate experiments to assess hatch and

825 emergence survival separately, and therefore, while emergence survival appears to be higher than 
826 hatch survival in two study sites in Spawn Creek, survival was estimated from two separate

827 experiments for hatch and emergence. Error bars are 1 standard error.

828

829 Figure 6. Relationship between level of fine sediment, calculated as proportion of fines, 830 standardized by the maximum weight of fines, and (A) percent hatch survival (logit(hatch

831 probability) $=-0.0110 *$ fine sediment $+1.220 ;$ Wald chi-square for slope $=86.1594, \mathrm{P}<0.001)$

832 and $(B)$ percent emergence survival (logit [emergence] $=-0.0128 *$ fine sediment +1.0647 ;

833 Wald chi-square for slope $=151.5350, \mathrm{P}<0.001)$.

834

835 Figure 7. Mean daily temperatures in Spawn Creek, Beaver Creek, Temple Fork, and Franklin

836 Basin during the course of the egg-to-fry experiment (1 July - 8 August). Minimum and

837 maximum temperature thresholds refer to the temperature range recommended for cutthroat trout

838 spawning. The optimal temperature line refers to the optimal temperature recommended for

839 cutthroat trout embryo incubation (Hickman and Raleigh 1982). 